\title{
Subcritical quenching process for toughness improvement of low alloy steel for perforating gun
}

\author{
Lixin Zhao ${ }^{1, a}$, Lingxue Zhen ${ }^{1}$, Liyun Zheng ${ }^{1}$, Yabin Zhang ${ }^{2}$ \\ ${ }^{1}$ School of Equipment Manufacture, Hebei University of Engineering, Handan, Hebei 056038 China \\ ${ }^{2}$ Xinxing Ductile Iron Pipes Co.,Ltd, Wuan, Hebei 056300 China \\ azhaolx1120@126.com
}

Keywords: alloys, mechanical properties, impact test, hot working

\begin{abstract}
To improve the impact toughness of the perforating gun pipe, subcritical quenching processes were designed and the influences of process parameters and the initial heat treatments on the mechanical properties of the steel were investigated. The results show that the hardness of the steel with an initial full quenching plus tempering increased at first, reached a highest value and then decreased with the increase of subcritical quenching temperatures. The higher tempered temperatures induced higher impact energy and cross-section reduction rate of the treated specimens and a slightly lower strength. When the initial heat treatments were as-quenched and as-annealed, the specimens subjected to the same subcritical quenching and tempering process had lower impact toughness than that with an initial heat treatment of full quenching plus tempering. The latter had much finer ferrites that separates the martensites maximizely, whilst the other two had large bulk ferrites that are detrimental to the impact toughness.
\end{abstract}

\section{Introduction}

The usage of perforating gun is crucial for well completion and increasing the productivity of the well. [1-3] The perforating gun must have both high strength and high ductility. The perforating gun will be seriously deformed or even cracked with the internal burst pressure if there are some improprieties in their design or manufacture. [4,5]At present, to obtain an ultra-high strength of over $130 \mathrm{ksi}$ for low-alloy high-strength steel in the field of perforating gun pipe is very challenging. $20 \mathrm{Mn}$ steel with small amount of other alloying elements such as Ti, Al and $\mathrm{Cr}$ is usually used as perforating gun pipe. Cr-Mo steel is another appropriate candidate that can also obtain ultrahigh strength if its microstructure can be well tuned.

The conventional quenching process for perforating gun pipe is usually quenching at $900{ }^{\circ} \mathrm{C}$ plus tempering at $560{ }^{\circ} \mathrm{C}$ to get sorbite as well as better comprehensive mechanical properties. But there may produce deformations and cracks for perforating gun pipe due to high heating temperature and long heating time. Subcritical quenching can get a two-phase coexistence microstructure of martensite and ferrite. This study investigates the relationship of subcritical quenching process, initial heat treatment status and the microstructures, mechanical properties of a novel Cr-Mo steel with finely tuned composition and provides information that will play an important role in the development of advanced subcritical quenching process for perforating gun.

\section{Experimental Procedures}

The chemical composition of the as-rolled experimental material is given in Table 1. These as-rolled materials were divided into three groups to perform heat treatment and characterization of microstructure and properties.

Table 1. Chemical composition (in wt $\%$ ) of the Cr-Mo steel investigated

\begin{tabular}{cccccccccccccc}
\hline $\mathrm{C}$ & $\mathrm{Si}$ & & $\mathrm{M}$ & $\mathrm{P}$ & $\mathrm{S}$ & $\mathrm{N}$ & $\mathrm{Cr}$ & $\mathrm{M}$ & $\mathrm{Al}$ & $\mathrm{Fe}$ \\
& & $\mathrm{n}$ & & & & $\mathrm{i}$ & & & $\mathrm{o}$ & & \\
\hline 0. & 0. & & 0. & 0. & 0.0 & 0 & 0. & 0. & 0. & $\mathrm{~B}$ \\
26 & 20 & 9 & & 01 & 05 & .1 & 95 & 42 & 02 & al. \\
\hline
\end{tabular}


The critical temperatures of the as-rolled materials were measured by using a differential thermal analyzer. The sequence was composed of two steps, first, temperature rising rate (Rt) was $10^{\circ} \mathrm{C} \mathrm{min}^{-1}$ and the end temperature (Te) was $700{ }^{\circ} \mathrm{C}$; second, Rt and Te were $5{ }^{\circ} \mathrm{C}$ min- 1 and $1050{ }^{\circ} \mathrm{C}$. Nitrogen was used as protection atmosphere and its flow rate was $15 \mathrm{ml} \mathrm{min}-1$. From the test results, the austenite start temperature, Ac1, and the complete austenitizing temperature, Ac3, were $765.3{ }^{\circ} \mathrm{C}$ and $859.6{ }^{\circ} \mathrm{C}$, respectively.

In a series of experiments, the as-rolled materials were initially subjected full quenching and tempering at $900{ }^{\circ} \mathrm{C}$ and $560{ }^{\circ} \mathrm{C}$, respectively (specimen A). Some specimens A were heated at 820 , 830,840 and $850^{\circ} \mathrm{C}$ for $40 \mathrm{~min}$ and cooled by water. After characterization, an optimized quenching temperature was chose as $840{ }^{\circ} \mathrm{C}$. Some specimens A quenched at $840{ }^{\circ} \mathrm{C}$ were heated at 540, 560, 580 and $600{ }^{\circ} \mathrm{C}$ for $80 \mathrm{~min}$ and tempered in air.

Some as-rolled materials were initially subjected to an annealing process, heating at $850{ }^{\circ} \mathrm{C}$ for 60 min and then cooling in the furnace (specimen B). Some as-rolled materials were initially subjected to a quenching process, heating at $900^{\circ} \mathrm{C}$ for $40 \mathrm{~min}$ and cooling by water (specimen C). Specimen $\mathrm{B}$ and $\mathrm{C}$ were all quenched at $840^{\circ} \mathrm{C}$ and tempered at $560{ }^{\circ} \mathrm{C}$ and compared with specimen $\mathrm{A}$ treated by the same subcritical quenching process.

The mechanical properties were measured using the average of five experimental results for each experimental condition. Charpy V-notch impact testing was conducted according to ASTM E23 standard conditions. The size and geometry of the specimens as well as the testing procedure were also based on the ASTM E8 standards for tension testing. Hardness measurements were done by the Rockwell hardness method in accordance with ASTM E18 standards. The optical microscopy specimens were prepared using a $4 \%$ nital solution. The specimens for grain size characterization were prepared using a saturated picric acid solution. The grain size analysis was carried out by an intercept method according to ASTM E112 standard conditions using an optical microscope.

\section{Results and Discussion}

Fig. 1 shows the photomicrographs of the specimens quenched at different temperatures. As compared to the conventional full quenching process, where the heating temperature is the complete austenitizing temperature plus $50-70{ }^{\circ} \mathrm{C}$ making free ferrite fully dissolved into the austenite, the subcritical quenching has a low heating temperature, allowing some free ferrite maintained out of the austenite and getting a two-phase structure of ferrite and martensite. From Fig. 1, we can see that the amount of the remained ferrite in the microstructure of the specimens reduced with the increase of the quenching temperature due to the amount of ferrite that dissolved into austenite increased.

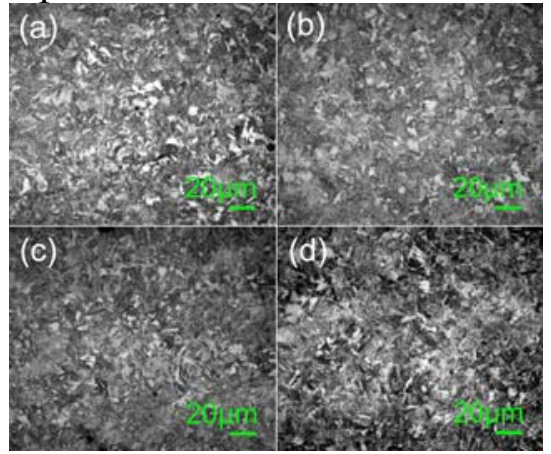

Fig. 1. Photomicrographs of the specimens of group A quenched at (a) $820^{\circ} \mathrm{C}$,

(b) $830^{\circ} \mathrm{C}$, (c) $840^{\circ} \mathrm{C}$ and (d) $850^{\circ} \mathrm{C}$

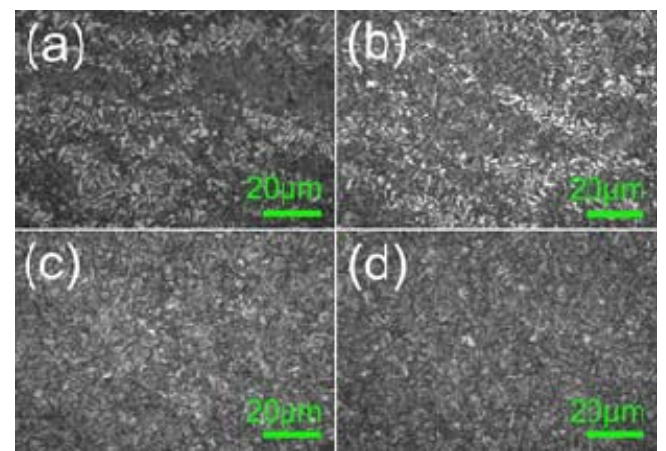

Fig. 2. Photomicrographs of specimens of group A quenched at $840^{\circ} \mathrm{C}$ and tempered at (a) $540{ }^{\circ} \mathrm{C}$, (b) $560{ }^{\circ} \mathrm{C}$, (c) $580{ }^{\circ} \mathrm{C}$ and (d) $600{ }^{\circ} \mathrm{C}$

The average grain sizes of the as-quenched specimen were 8.25, 9.24, 9.51 and $10.08 \mu \mathrm{m}$ and the average hardnesses were HRC45.9, HRC46.7, HRC48.5 and HRC47.8 when the quenching temperatures were $820,830,840$ and $850{ }^{\circ} \mathrm{C}$. The hardness values of the specimens increased at the initial temperature rising stage and then decreased with further increase of temperature. With the increase of quenching temperature, a large amount of ferrites with low hardness were dissolved into austenite and large quantities of martensites with high hardness were obtained. Thus, the amount of 
remained ferrite decreased and the amount of martensite increased, which contributed to a higher hardness. But when the temperature increased to $850{ }^{\circ} \mathrm{C}$, the amount of residual austenite increased consequently, leading to a decrement of hardness.

To get a good match of grain size and hardness, the optimized subcritical quenching temperature was selected at $840{ }^{\circ} \mathrm{C}$. The specimens of group A was heated at $840{ }^{\circ} \mathrm{C}$ for $40 \mathrm{~min}$ and quenched by water. And then these quenched specimens were heated at 540, 560, 580 and $600{ }^{\circ} \mathrm{C}$ for 80 min and cooling in air for tempering. Fig. 2 shows the photomicrographs of specimens of group A quenched at $840{ }^{\circ} \mathrm{C}$ and tempered at different temperatures. It is clear that the microstructures of these specimen composed of ferrite, tempering sorbite and the well-dispersed small residual austenite.

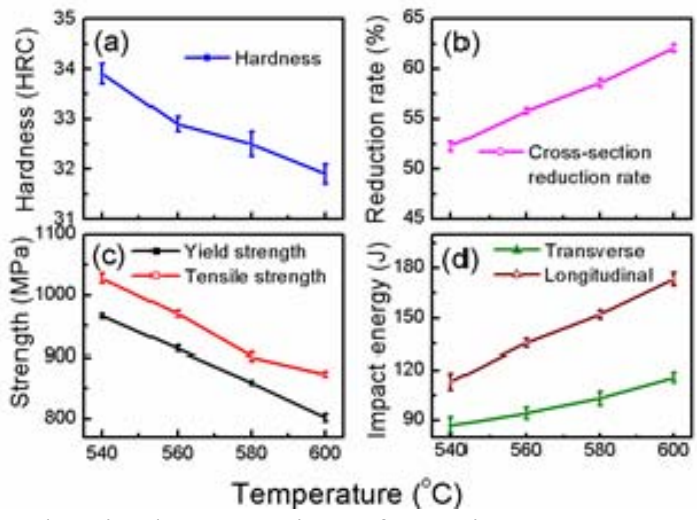

Fig. 3. Mechanical properties of specimen A after subcritical quenching and tempering

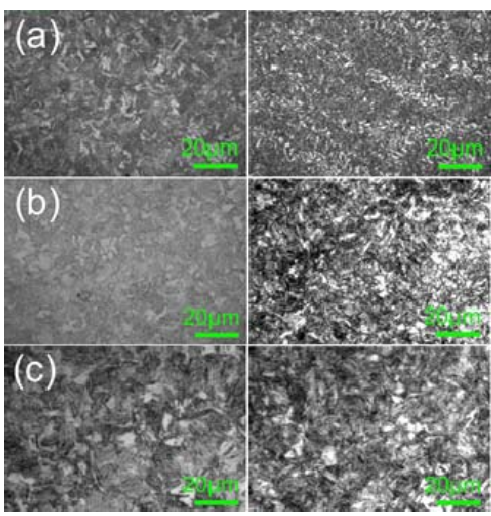

Fig. 4. Photomicrographs of the subcritical quenched (left column) and tempered (corresponding right column) specimens with initial heat treatment of (a) full quenching and tempering, (b) annealing, (c) quenching

Fig. 3 shows the mechanical properties of the specimens of group A after subcritical quenching process. As we expect that the cross-section reduction rate and impact energy increased apparently and the hardness and strength lightly decreased with the increase of tempering temperatures. Comparing with the initial full quenching and tempering conditions, the specimen after subcritical quenching and tempering process got an enhancement of impact toughness. This may be due to that the specimen subjected subcritical quenching process was heated at a temperature lower than phase transition point Ac3. So, there were some undissolved ferrites in the subcritical quenched microstructure. The formed austenites were separated by the undissolved ferrites that hindered the growth of austenite grain and led to a fine grain, which contributed to the toughness. At the same time, the undissolved ferrites have high toughness and were preserved in the tempered microstructure. Thus, the area of the preserved ferrites plus the residual austenites was larger than that of the microstructure with only residual austenites after conventional quenching process, which also contributed to the toughness.

Fig. 4 shows the photomicrographs of the subcritical quenched and tempered specimens with different initial heat treatments. The subcritical quenching process is heating at $840{ }^{\circ} \mathrm{C}$ for $40 \mathrm{~min}$, quenching by water, heating at $560{ }^{\circ} \mathrm{C}$ for $80 \mathrm{~min}$ and tempering in air. The mechanical properties of these specimens are shown in Table 2.

Table 2. Comparison of mechanical properties of the specimens with different initial heat treatments before and after subcritical quenching and tempering

\begin{tabular}{ccccc}
\hline Specimens & Original A & Treated A & Treated B & Treated C \\
\hline Hardness (HRC) & $31.2 \pm 0.2$ & $32.9 \pm 0.15$ & $26.9 \pm 0.3$ & $35.2 \pm 0.2$ \\
Yield strength (MPa) & $927 \pm 6$ & $913 \pm 5$ & $935 \pm 9.5$ & $871 \pm 12$ \\
Tensile strength (MPa) & $998 \pm 4$ & $970 \pm 5$ & $992 \pm 8$ & $896 \pm 11$ \\
Cross-section reduction rate & $51.6 \pm 0.5$ & $55.8 \pm 0.3$ & $53.2 \pm 0.4$ & $49.1 \pm 0.4$ \\
$(\%)$ & & & \\
Transverse impact energy (J) & $74.5 \pm 4.7$ & $94.3 \pm 2.5$ & $78.95 \pm 3.75$ & $69.95 \pm 4.9$ \\
Longitudinal impact energy $(\mathrm{J})$ & $119.7 \pm 4.8$ & $135.3 \pm 3.6$ & $124.3 \pm 3.6$ & $116.7 \pm 5.5$ \\
\hline
\end{tabular}


From Fig. 4 (right column), we can see that the microstructures of the subcritical quenched and tempered specimens with different initial heat treatments consisted of tempering sorbites and preserved ferrites. The subcritical quenched and tempered specimen A with an initial full quenching and tempering process had a much fine microstructure. The average grain sizes of the quenched and tempered B, C and A were 12, 10.35 and $9.51 \mu \mathrm{m}$, respectively. Specimen A showed a significantly fine and uniform grain size. From the microstructures of the quenched specimens (Fig. 4 left column), the specimen A also showed much fine structures. The microstructures were composed of ferrites and martensites in all three specimens after subcritical quenching. But there were some large bulk ferrites in the specimen $\mathrm{C}$. This is because that the initial microstructure of specimen $\mathrm{C}$ was non-equilibrium microstructure rather than equilibrium microstructure like specimen $\mathrm{A}$ and $\mathrm{B}$. For the nonequilibrium microstructure, the martensite is much coarse before subcritical quenching. The transformation power is provided during the reheating process of subcritical quenching and carbides are nucleated and precipitated directionally. [6] When the temperature reaches the two-phase region, the carbons of the martensites are desolventized and the martensites become ferrites. Thus, the ferrites inherit the coarse orientation of the martensite and appear in coarse block after subcritical quenching.

From Table 2, specimen A with an initial full quenching and tempering process met the requirements of mechanical properties of $130 \mathrm{ksi}$ grade steel for perforating gun and had excellent impact toughness. For biphase alloy, the microstructures have great effect on the mechanical properties, which is favor of impeding the growth of cracks. When the ferrite appears in needle-like, it can divide the martensite maximizely. Thus the crack growth has to pass not only brittle martensite but also plastic ferrite, producing larger plastic strain before deformation, consuming a plenty of energy, hindering the growth of crack. But when the ferrites are large blocks, the crack will go through the martensite matrix and make a detour around the ferrite blocks, leading to a weak toughness. Therefore, specimen A with needle-like ferrites and fine two-phase microstructures had excellent comprehensive mechanical properties.

\section{Conclusions}

The low alloy steel was performed subcritical quenching process and the microstructures and mechanical properties had been investigated. We may have a conclusion that specimen with an initial full quenching and tempering process obtained higher comprehensive mechanical properties after subcritical quenching and tempering. The optimized subcritical quenching process was heating at 840 ${ }^{\circ} \mathrm{C}$ for 40 min, quenching by water, then heating at $560{ }^{\circ} \mathrm{C}$ and tempering by air. The mechanical properties of the specimen subjected the above heat treatment not only reached the requirement of $130 \mathrm{ksi}$ grade steel but also reduced the deformation and crack of the component during the heat treatment process.

\section{Acknowledgments}

The authors acknowledge the support of Hebei Natural Science Funds for Distinguished Young Scholars under Grant No.E2013402051.

\section{References}

[1] F. Bruyere, D. Clark, G. Stirton, et al, Oilfield Review, Autumn, 18 (2006).

[2] Patent No. WO2014056890A2, Filing on Oct 8, 2013, Publication on Apr 17, 2014.

[3] Patent No. US 5477785 A, Filing on Jan 27, 1995, Publication on Dec 26, 1995.

[4] K.J. Li, Oil Field Equipment, Lanzhou of China, 8, 46 (1997). (in Chinese)

[5] L.A. Behrmann and J.L. Elbel, Journal of Petroleum Technology May, 608 (1991).

[6] B.-S. Lee, G.W. Burr, R.M. Shelby, et al, Science, 326, 980 (2009). 